\title{
E-Training Engineers in Rehabilitation of Buildings and Knowledge Management: Project HKNOW
}

\author{
Alfredo SOEIRO

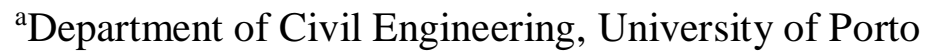 \\ Corresponding Author: avsoeiro@fe.up.pt, Tel: +351919738291
}

\begin{abstract}
The project is motivated by the increasing number of complex works of rehabilitation of buildings that require rapid and systematic access to specific knowledge. The approach is to facilitate access to proper knowledge through collaborative business networks formed by companies and research and development partners. This project aims at: (a) providing a learning community of fundamental knowledge and an organization of tacit knowledge of SMEs and (b) allowing closer business collaboration between SMEs and RDs. The project plans to develop solutions based on information technology and communication that are adequate for SMEs, including knowledge sharing and training for engineers.
\end{abstract}

Key words: building rehabilitation, knowledge management, network, e-learning, training

\section{Project Analysis}

The project title is "Advanced Infrastructure for Knowledge Based Services for Restoring Buildings". It makes part of the funding program of Theme 4 - of the $7^{\text {th }}$ Framework Program of the European Commission. It is a sub-program entitled Project Collaboration Aimed at Small and Medium Enterprises (SMEs). The project has a total funding of about 1.9 M $€$ and a total cost of about $2.6 \mathrm{M} €$. It has fifteen partners from five countries: Portugal, Italy, Germany, France and Spain. The increasing number and complex work in the construction industry, particularly for the renovation, restoration and maintenance of buildings of old buildings, often belonging to buildings of architectural and cultural heritage, suggests a systematic and sophisticated approach allowing access to advanced and knowledge about the processes and materials of construction in this area. Innovative solutions using collaborative networks of knowledge and involving business partners, SMEs, and research and development (RD) need to be created and tested. Thus, SMEs that deal with the maintenance and repair of buildings are faced with two problems like:

a) Being able to respond to increasing demands for the implementation of the rehabilitation processes, application expertise, process technology and new materials, and ensure a high satisfaction of the work owners. All this is accompanied by pressure to reduce material and energy consumption and hence create a need for SMEs to have access to knowledge about other works and other contractors in the industry. To facilitate this ongoing access to knowledge components for application in different projects the project proposes an efficient collaboration between SMEs and RDs. Such knowledge will be of added value for purposes of learning and training. Innovative solutions in collaborative networks of knowledge are based on learning in a two-way procedure between SMEs repositories and RDs functioning.

b) Establish closer collaboration within the sector through an alliance of SMEs and RDs. This may create cooperative teams to handle complex works. Networking will ensure higher efficiency of processes and integration of services with added value for engineering rehabilitation. Solutions may support pace of economic development based on knowledgebased systems that have been developed using Information and Communication Technologies (ICT). This may be used in infrastructure, in tools and in services supporting the creation of integrated knowledge networks. Such systems need to be integrated with learning systems 
that must support the organization with training on topics specific to engineers and technicians. These solutions for users of ICT should be accessible, friendly and intuitive to use by SMEs in terms of cost and complexity.

\section{Objectives of HKNOW}

Concerning the two challenges described above the project plans to develop a solution based on ICT with two goals: (1) knowledge and training for SMEs that are innovative and (2) support for advanced development and for ways of networking of SME-RD. The system must provide ability to share, to create and to reuse information and knowledge in an interactive fashion. To meet the needs of SMEs to network innovative knowledge-based, the HKNOW project will develop an electronic platform, in which the services of knowledge management will be complemented by services for virtual collaborative networks (VCN).

This management of knowledge will allow an effective combination of an advanced system of provision of knowledge and training with an innovative support system of networking. It will respond to the following requirements: (1) Internet-based, (2) usable by SMEs (in terms of costs investment and human resources), (3) ensuring permanent access to specific resources of knowledge and experts, (4) recording the knowledge generated through the work of rehabilitation and structuring it in formats for learning and reutilization, (5) using open formats supporting cooperation in the rehabilitation process, (6) supporting mobile users access to a structure anywhere and at any time. To achieve these objectives the proposed HKNOW includes research on:

a) The methodology for creation of $\mathrm{VCN}$ for SME-RD, supported by a set of models and methods for creating the network and the procedures for structuring and managing knowledge, tailored specifically for SMEs.

b) Platform support, hosting a range of services to (1) manage interactions, (2) ensure knowledge management and (3) provide e-learning. The platform should allow the interactive share knowledge between SMEs and RDs within VCN.

c) All ICT services encouraging collaboration, allowing workers in SMEs to provide answers in different contexts.

d) Services of knowledge management within RD-SME networks.

e) Definition and development of adequate e-learning establishing the link between the knowledge created and used in rehabilitation projects taking into account the SME needs and level of education.

Each case study can originate a contribution to a specific field of rehabilitation work in construction, creating and using specific knowledge. The system is open for adding and structuring knowledge in all areas of rehabilitation (restoration and maintenance) of the construction industry. The project aims to use emerging technologies to create collaborative networks based on principles of a service-oriented architecture as an optimal approach for dealing. It is intended that the combination of e-learning and knowledge management provides the desired skills for the benefit of all and allows the creation of innovative training.

\section{Organization and Workplan}

The organizational structure was implemented to apply the approach of architecture-based services using the collaborative system of reference [1]. The platform will include the tasks outlined that are directly connected to the set of information related to knowledge and learning resources. The experiences of previous projects that used a similar architecture, including collaboration on the production of services were carried out for various industrial 
applications [2]. The CSR will combine services with the specific services of various collaborative applications to support the SME-RD teams directly in specific activities of rehabilitation.

The analysis of requirements from users indicates that these uses require different support for: (a) collaborations with different patterns with a predominance of temporal aspects: patterns synchronous, asynchronous and multi-synchronous, (b) the workplace environment in VCN, including identification experts, staff training, availability, etc.., (c) actual delivery (online) knowledge about processes and about actors, (d) effective knowledge management, (e) changes of the dynamics of collaborative work during the development process, (f) decisionmaking in VCN. The proposed solution will include common services, which deal with generic applications, independent features to support collaboration, dealing with common activities such as demand for resources, registration of previous collaborations, providing knowledge, etc..

HKNOW is a project oriented towards end-user. The sequence of activities can be found in Figure 1. The division consists of seven stages in the working groups, which are:

a) at the beginning of the project end-users, RDs and SMEs, may define the desired scenarios and identify solutions to validate the outcome of the project;

b) at the same time, there will be a survey of methods, tools and technologies so that scenarios can be created for evaluation by potential end users;

c) after identification of the requirements of end users the project HKNOW develops methods, platforms and services in order to validate the results of the project;

d) the methodology and ontology of the project will be developed to test knowledge relevant to the project;

e) a prototype that will be developed in order to test, with end users, the features and capabilities of the model;

f) the prototypes that will be installed on servers for end-users of the project to create a work environment that enables collaboration;

g) the four models of the project involving partners from five countries will be installed and used as a demonstration in the rehabilitation of buildings.

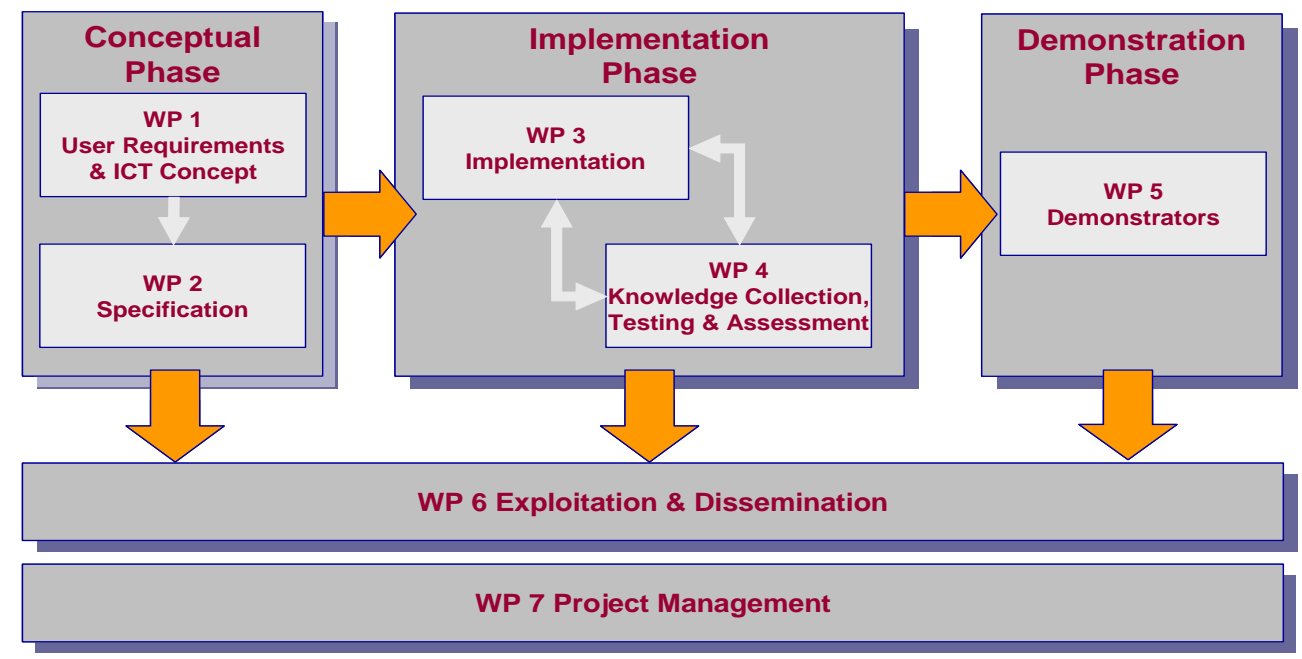

Figure 1. Project Phases and Workplan (project proposal) 


\section{Engineer Training}

The training envisaged for engineers and technicians involved in building rehabilitation imposed certain specifications that will be supported by ICT. This is being denominated in the project as Technology-Enhanced Learning (TEL). The TEL services will be based on an existing Moodle platform that works as an open Learning Management System (LMS). The application of these services for the users and for the users tasks are defined with emphasis on using proven authoring tools to create learning content that is reusable and can be recomposed [3]. The user types of these TEL learning services are based on the description of the HKNOW business cases that were researched during the first part of the project. The roles can be course organizer, teacher, mentor, learning material or course participant. The tasks performed by the users can be organizing a course, managing a course, create a learning object or a lesson and participate on collaborative learning.

The functions required for the Moodle platform for course creation and use are [4]:

a) Learning Objects/Lessons creation: create learning object/lesson; define instructional goal; request specific content/knowledge, on a particular topic; compile learning object/lesson based on specific content/knowledge; adjust learning object/lesson to the intended audience.

b) Learning group composition: compose learning group; define minimum expertise necessary for joining the learning group (prerequisites); search candidate learning group members; select candidate learning group members; invite members to join the learning group.

c) Course organization and management: organize and manage course; search appropriate course attendants from an existing learning group, based on criteria like availability and expertise; define lessons planned for the course; define course dates and time period; define list of mentors associated to the course; define preferred communication ways and collaboration patterns; define course schedule/flow; notify course attendants; enroll course attendant; enable learning path; allocate access rights; services for collaborative learning; learn collaboratively; use virtual classroom; audio/video chat; share applications.

According to the user requirements and specifications several options were considered [5]. The general layout is presented in Figure 2. It is an option based on the interaction of the other requirements of the HKNOW platform with the TEL functionalities.

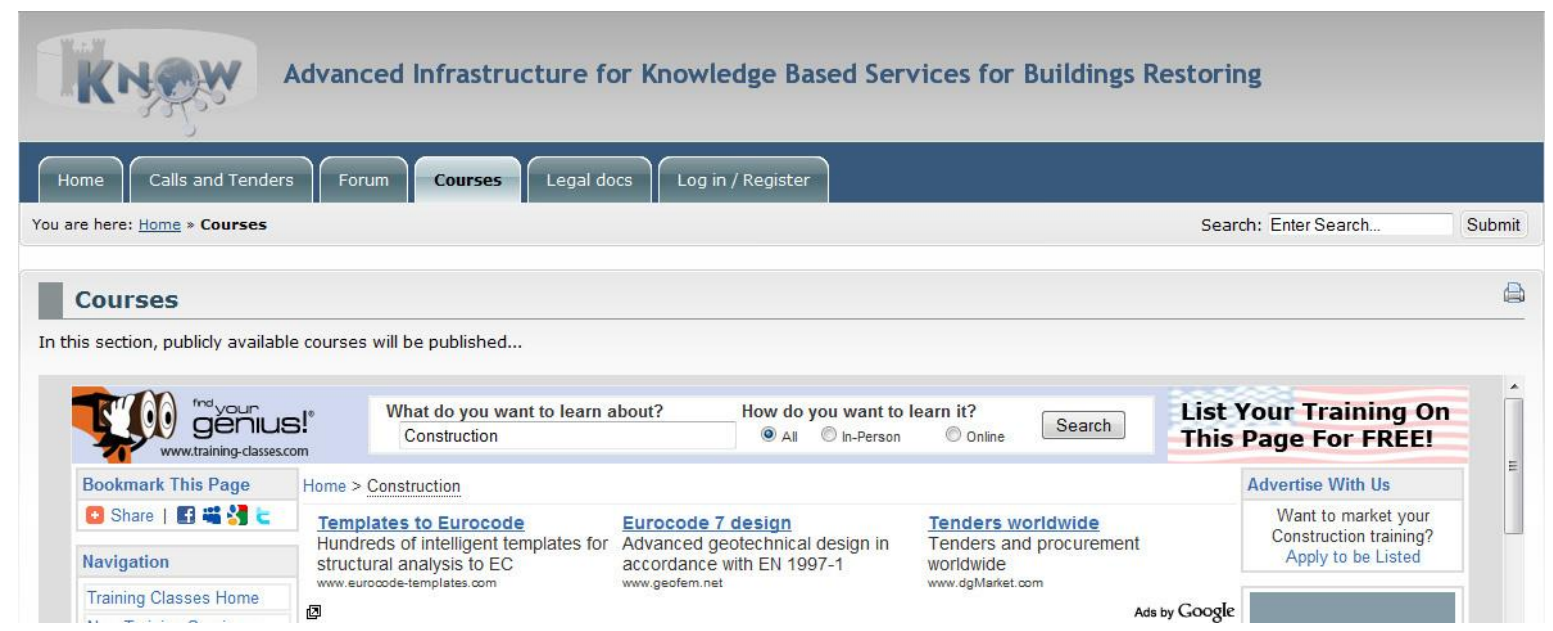

Figure 2. Example of Moodle Platform Layout 


\section{Conclusions}

As a result of the previous considerations there are some decisions taken to implement the learning and training for continuing engineering education (CEE) in the HKNOW Project. The CEE courses created by the HKNOW platform will be organized in general areas and sub-areas that will be defined with the help of SME's and of RDs. The HKNOW project will provide a system that allows that:

a) Platform users, including non-registered users, should be able to see not only a list of free courses but also the courses with costs that the network has to offer. This is a tactic to promote collaboration among participants, to share useful knowledge and to attract new users to the project VCN.

b) Courses offered by the platform HKNOW should present general information like: name, summary, contents, modules, costs and access procedure.

c) The HKNOW platform used for knowledge management and networking is based on a Drupal open source content management system. To interact with the LMS Moodle a single sign-on procedure was created allowing exchange among the two environments.

d) Allow online creation of the learning objects and development of lessons/courses with, for instance, learning objects delivered by SME's know-how and by RD organizations.

e) Classifying training courses with two options as free courses or paid courses.

The junction of different types of electronic knowledge management and collaboration systems was the strategy adopted to respond to the different requirements of the project. It is expected that this option will bring cohesion and added value to handle the knowledge management, the cooperation environment and the learning and training resources to the engineering community. Rehabilitation of buildings is a difficult are of work and only with proper handling of information/knowledge, of professional networking and of training it is viable to increase productivity and quality.

\section{References}

[1] Ralli, C., Collaboration Reference Architecture, Workshop on e-Collaboration in working environments, VUB, Brussels, November, 2005.

[2] Bekhti, S. \& Matta, N., Traceability and knowledge modeling, COOP2002, 2002.

[3] Rice, W., Moodle 1.9 E-learning, Packt Publishing, 2008.

[4] Armijo, J. et al, HKNOW M18 Report, www.h-know.eu, 31Jul10.

[5] Cole, J. and Foster, H., Using Moodle, O’Reilly Media, CA, USA, 2008. 